\title{
Substituents on Quinone Methides Strongly Modulate Formation and Stability of Their Nucleophilic Adducts
}

\author{
Emily E. Weinert ${ }^{1}$, Ruggero Dondi ${ }^{2}$, Stefano Colloredo-Melz ${ }^{2}$, Kristen N. Frankenfield ${ }^{1}$, \\ Charles H. Mitchell ${ }^{1}$, Mauro Freccero ${ }^{2,}$, , and Steven E. Rokita ${ }^{1,}$ \\ 1 Department of Chemistry and Biochemistry, University of Maryland, College Park, MD, 20742 USA \\ 2 Dipartimento di Chimica Organica, Università di Pavia, V.le Taramelli 10, 27100 Pavia, Italy
}

\begin{abstract}
Electronic perturbation of quinone methides $(\mathrm{QM})$ greatly influences their stability and in turn alters the kinetics and product profile of QM reaction with deoxynucleosides. Consistent with the electron deficient nature of this reactive intermediate, electron-donating substituents are stabilizing and electron-withdrawing substituents are destabilizing. For example, a dC N3-QM adduct is made stable over the course of observation (7 days) by the presence of an electron-withdrawing ester group that inhibits QM regeneration. Conversely, a related adduct with an electron donating methyl group is very labile and regenerates its QM with a half-life of approximately $5 \mathrm{hr}$. The generality of these effects is demonstrated with a series of alternative quinone methide precursors (QMP) containing a variety of substituents attached at different positions with respect to the exocyclic methylene. The rates of nucleophilic addition to substituted QMs measured by laser flash photolysis similarly span five orders of magnitude with electron rich species reacting most slowly and electron deficient species reacting most quickly. The reversibility of QM reaction can now be predictably adjusted for any desired application.
\end{abstract}

\section{Introduction}

Developing reagents for selective reaction with cellular components is often dismissed due to an unnecessary assumption that covalent processes are limited to irreversible chemistry. Reversible covalent reaction has the potential to overcome kinetic traps that limit both potency and selectivity. Reactive species may be regenerated repeatedly in a reversible process to escape trapping with non-targeted materials and even overcome cellular repair processes. The ability of the natural product Ecteinascidin 743 (Et-743) to bind covalently to duplex DNA and yet still migrate between various nucleotide sequences, for example, also allows Et-743 to reassociate with DNA after its initial adduct has been removed by excision repair (Scheme 1). ${ }^{1}$ In contrast, reagents such as nitrogen mustards react irreversibly with strong nucleophiles in DNA, most notably the N7 of guanine (Scheme 2 ) and other cellular compounds. ${ }^{2-4}$ The most significant effect of the mustards, DNA cross-linking, only proceeds if a second nucleophile is proximal to the initial site of attachment. However, this second nucleophile is not typically present and reaction is quenched before the mustard can migrate to a site in DNA that would support cross-linking.

Reversible alkylating agents may also react with a range of cellular components, but after multiple regenerations they may ultimately associate with their thermodynamically favorable targets (e.g., Et-743 with duplex DNA, Scheme 1). Reversibility then extends the effective 
lifetime of electrophiles and consequently enhances their potential for selective biological activity. Such activity has been investigated with carcinogens such as malondialdehyde $5-8$ and a variety of anticancer drugs candidates based on cyclopropylpyrroloindole. ${ }^{9,10}$ For two closely related drug candidates, duocarmycin SA (duoSA) is twenty-fold more cytotoxic than duocarmycin A (duoA). This result is likely a function of the slower reaction of duoSA vs. duoA with nucleophiles and its faster release from adducts formed by nucleophilic coupling. 11,12 A direct correlation between reversibility of DNA adducts and cytotoxicity was also extended to a number of additional cyclopropylpyrroloindole derivatives as well. ${ }^{13}$

Our laboratories and others have applied the reversibility of quinone methide (QM) generation for efficient cross-linking and target-promoted alkylation of DNA. ${ }^{14-18}$ Related QMs had previously been implicated in the biological activation 2,6-ditert-butyl-4-methylphenol, 19 tamoxifen $^{20}$ and a variety of natural products including mitomycin ${ }^{21}$ and certain diterpenone catechols. $^{22}$ Initial model studies suggested a selectivity of QM for weak nucleophiles and an ability of some adducts to form reversibly. ${ }^{19,23-26}$ Further investigation revealed that this unusual selectivity was a function of QM adduct stability rather than initial product formation. 27-29 In contrast to earlier assumptions, the strongest nucleophiles of DNA reacted most quickly with a simple ortho-QM model to form kinetic products. However, these products are not stable and regenerate the ortho-QM for ultimate transfer to weaker nucleophiles that react irreversibly and form thermodynamic products (Scheme 3 ). 27,30

Computational studies on this same ortho-QM model anticipated the experimental results with remarkable accuracy. ${ }^{28,29}$ A low value for $\Delta \mathrm{G}^{\ddagger}$ was calculated for both adduct formation and QM regeneration with strong nucleophiles such as dC N3, dA N1 and dG N7 (Scheme 2) whereas $\Delta \mathrm{G}^{\ddagger}$ values for addition of the exo-amino groups $\left(\mathrm{dG} \mathrm{N}^{2}\right.$ and $\left.\mathrm{dA} \mathrm{N}^{6}\right)$ to ortho-QM were considerably higher and essentially irreversible. The free energy of activation should also be sensitive to variations in the electronic properties of the intermediate QMs. A relatively electron-rich derivative may be more stable and hence more readily generated than its electronpoor counterpart. Hence, electron withdrawing and donating groups attached directly on the QM should influence the rate of QM formation and adduct stability. A series of such derivatives has now been prepared to test this possibility and determine the sensitivity of the QM to a variety of substituents. A method for predictably manipulating QM stability will be indispensable for optimizing the kinetics and selectivity of target promoted alkylation of DNA $^{15}$ and will additionally facilitate use of QM for mechanism-based inactivation of enzymes $^{31}$ and drug release by self-immolative, or cascade-release, dendrimers. ${ }^{32-34}$ Quinone methides are also used as intermediates in organic synthesis 35 and can be stabilized by metal coordination. ${ }^{36-39}$

\section{Results and Discussion}

A limited number of studies previously began to explore substituent effects on QM reactivity, $40-43$ but no data was available to estimate structural effects influencing the kinetics or product distribution of deoxynucleoside reaction. Electron donating and withdrawing groups have now been placed para and meta to the QM methylene to avoid complications from steric effects. The products of reversible reaction were expected to be most susceptible to changes in the QM stability since their presence depends on the rates of both nucleophilic addition to the QM as well as subsequent elimination to regenerate the QM. In contrast, the products formed irreversibly should depend on only the relative strength of their nucleophilic components to compete for initial addition to the QM.

\section{Formation and Decomposition of dC Adducts Generated from QMs of Varying Reactivity}

Our initial investigation to determine the extent to which QM reactivity can be controlled by aromatic substituents was performed with $\mathrm{dC}$ since this deoxynucleoside forms a single adduct 
upon incubation with QM1. ${ }^{44}$ The quinone methide precursor (QMP1) originally used to generate the unsubstituted QM1 was also modified alternatively with a methyl (QMP2) and methyl ester (QMP3) group to examine the effect of electron donating and withdrawing groups, respectively (Scheme 4). As described previously, fluoride was used to initiate deprotection of the QMPs. ${ }^{44}$ Subsequent elimination of acetate generated the QMs for $\mathrm{dC}$ alkylation. Both QM2 and QM3 also generated only a single adduct with $\mathrm{dC}$ under the same conditions used previously to form the $\mathrm{dC} \mathrm{N} 3$ adduct of QM1. ${ }^{44}{ }^{1} \mathrm{H}$ NMR data for these new derivatives are consistent in each case with linkage through the $\mathrm{N} 3$ of $\mathrm{dC}$. The chemical shifts of the benzylic methylene protons are quite characteristic of QM adduct structure 25,26 and benzylic signals for the dC N3-QM adducts of QM1, QM2 and QM3 differ by no more than approximately $0.1 \mathrm{ppm}$ (Table 1).

Kinetic measurement of $\mathrm{dC}$ addition to the QMs was performed under conditions identical to those first used to follow reaction of QM1. ${ }^{30}$ The maximum yield of adduct formed in each case was similar, but their rates of formation and stability varied greatly (Figure 1). The $\mathrm{dC}$ N3 adduct of the electron-rich QM2 formed most rapidly, and a maximum yield was achieved in less than $1 \mathrm{hr}$. Decomposition of this adduct was also very rapid with a half-life of approximately $5 \mathrm{hr}$ and resulted in release of $\mathrm{dC}$ and presumably quenching of QM2 with water. In contrast, the unsubstituted QMP1 examined previously generated a maximum yield of dC N3-QM1 adduct after 4-10 hr. This product exhibited moderate stability under the reaction conditions and decomposed with a half-life of approximately $24 \mathrm{hr}$. Finally, the electron-poor QM3 formed very slowly over $40 \mathrm{hr}$, but the dC N3 adduct that resulted from its reaction persisted without change over a minimum of $72 \mathrm{hrs}$. No decomposition of the $\mathrm{dC}$ N3-QM3 adduct was even detected after an extended incubation of 7 days.

The rate of adduct formation primarily reflects the rate of initial QM formation by elimination of the benzylic acetate after rapid desilylation. Electron donation of a single methyl substituent stabilizes QM2 sufficiently to promote its formation by at least 4-fold relative to formation of QM1 (Figure 1 and Supporting Information). Similarly, QM1 forms perhaps 10-fold more rapidly than QM3 that contains an electron withdrawing group. This same trend is apparent for $\mathrm{QM}$ regeneration from each of the $\mathrm{dC} \mathrm{N} 3$ adducts. Thus, small changes in the electronics of the QMs affect their reactivity and adduct stability dramatically and now also predictably.

\section{Deoxynucleoside Competition with an Electron-rich QM}

The consequences of QM stability on the kinetics of forming all deoxynucleoside adducts was next examined with a competitive equimolar mixture of $\mathrm{dA}, \mathrm{dG}, \mathrm{dC}$ and $\mathrm{T}$ in analogy to earlier studies with the unsubstituted QM1 ${ }^{30}$ Product standards were first isolated after reaction with individual deoxynucleosides, and each product was characterized by ${ }^{1} \mathrm{H} N \mathrm{NR}$, high-resolution mass spectrometry (HRMS) and UV absorbance. Once again, the chemical shift of the benzylic protons was diagnostic of the linkage between the QMs and deoxynucleosides (Table 1). Characteristic changes in the UV absorbance maxima further confirmed the assignments (Supporting Information). Reaction of QM2 with dA yielded two adducts linked through its $\mathrm{N} 1$ and $\mathrm{N}^{6}$ positions. Only the $\mathrm{N}^{6}$ adduct was stable enough for isolation and characterization. However, the UV maximum of the second product was recorded during HPLC analysis and is consistent with an N1 adduct (Supporting Information). Three products were generated by QM2 and $\mathrm{dG}$ and identified as adducts of its N1, $\mathrm{N}^{2}$ and N7 positions. Both the N1 and $\mathrm{N}^{2}$ adducts were characterized as their $\mathrm{dG}$ derivatives. The $\mathrm{N} 7$ adduct of $\mathrm{dG}$ was evident during chromatographic separation but spontaneously deglycosylated to form its guanine derivative. This secondary product was stable and subject to standard analysis. Similar results had previously been observed with reaction of $\mathrm{dG}$ and QM1. 26,30 No adducts of T were observed under the range of conditions examined in this work. 
Monitoring the competitive reaction of $\mathrm{dA}, \mathrm{dC}, \mathrm{dG}$ and $\mathrm{T}$ with QMP2 over time resulted in the same trends observed previously with QMP1 except the timeframe of the evolving products was significantly compressed (Figure 2). The initial two hrs were dominated by reaction of the strong nucleophiles, dA N1 and dC N3. However, the resulting adducts decomposed with halflives of less than $4 \mathrm{hrs}$. The weaker nucleophiles in turn formed adducts more slowly over 8 $\mathrm{hr}$ and most likely as a result of QM2 regeneration from the adducts of dA N1 and dC N3. QM2 generation from its initial QMP2 precursor is nearly complete within the first $2 \mathrm{hrs}$ (Supporting Information). This again illustrates the ability of reversible adducts to extend the effective lifetime of an otherwise highly transient intermediate. The leaving group abilities of dA $\mathrm{N}^{6}$, dG N1 and dG $\mathrm{N}^{2}$ are not sufficient to regenerate the $\mathrm{QM}$, and thus their adducts remained stable over the course of observation.

Initial reaction at $\mathrm{dG} \mathrm{N7}$ is less than might be expected from its strong nucleophilicity. However, its adduct has the unique ability to deglycosylate as well as eliminate QM2. At the deoxynucleoside level, partitioning between deglycosylation and QM regeneration had previously been observed to occur at equivalent rates ${ }^{30}$ The deglycosylation product from reaction with QM2 accumulated over approximately $15 \mathrm{hrs}$ and remained stable since guanine N7 does not share the strong leaving group ability of dG N7. Although the kinetics of alkylation with QM2 were significantly faster than with QM1, all of the irreversible adducts were stable for at least six days beyond the observations of Figure 2. The nucleophilic sites used to create these adducts therefore still lacked the leaving group ability to eliminate from a QM with the added electron density provided by a pendent methyl group. This group was, however, sufficient to accelerate QM regeneration from adducts that had previously exhibited lability with QM1. ${ }^{30}$ Finally, the overall yields of stable adducts were similar for QM1 and QM2, and only minor differences in their relative formation was detected.

\section{Deoxynucleoside Competition with an Electron-poor QM}

Individual deoxynucleosides were also treated with the electron-poor QMP3 in order to generate synthetic standards for structural and chromatographic markers. Incubation of dA with QMP3 and fluoride resulted in adducts formed by its $\mathrm{N} 1$ and $\mathrm{N}^{6}$ positions. This is consistent with reactions of both $\mathbf{Q M 1}{ }^{27}$ and QM2. Additionally, the ${ }^{1} \mathrm{H}$ NMR signals for the benzylic positions were again diagnostic of their structures (Table 1). Comparable reaction of QMP3 with dG yielded only two products. These were isolated and identified as adducts of guanine $\mathrm{N} 7$ and $\mathrm{dG} \mathrm{N}^{2}$. The dG N7 adduct did not accumulate since its deglycosylation is likely faster than its formation due to the slow generation of QM3. The product of dG N1 alkylation was also not initially apparent but could later be formed when the concentration of $\mathrm{dG}$ was raised from the standard $0.25 \mathrm{mM}$ to $5.0 \mathrm{mM}$. Computational studies for QM1 indicated that reaction at dG N1 has an activation energy approximately $3 \mathrm{kcal} / \mathrm{mol}$ higher than that of $\mathrm{dG} \mathrm{N}^{2}$ as modeled with 9-methylguanine in water. ${ }^{29}$ This can be used to explain the greater yield of the dG N2 adduct over the yield of the dG N1 adduct with QM1 and QM3. Surprisingly, QM2 exhibited the opposite selectivity. The origin of this difference is currently subject to additional computational analysis. Once again, no reaction of $\mathrm{T}$ was detected.

Reaction of QMP3 with dNs was significantly slower than reaction with QMP1 due to electronic destabilization of QM3 from the attached methyl ester (Figure 3). Maximum accumulation of the $\mathrm{dC} \mathrm{N} 3$ adduct required more than $24 \mathrm{hr}$ and reflected a slow generation of QM3 from its desilylated derivative of QMP3 (Supporting Information). Additionally, this adduct was stable well beyond the $120 \mathrm{hr}$ period of observation (see above). The leaving group ability of dC N3 was thus insufficient to overcome the barrier to regenerate QM3 in contrast to its behavior with the more electron-rich QM1 and QM2 derivatives. The change in electronics between QM2 and QM3 did not greatly effect the maximum yield of the dC N3 adduct despite its conversion from a reversible to irreversible adduct, respectively. 
Formation of the dA N1 adduct similarly reflected the slow generation of QM3 (Figure 3). A maximum yield for this adduct required approximately $10 \mathrm{hrs}$ with QMP3 while less than 0.5 hr was necessary with the electron rich QMP2. Reversibility of the dA N1 adduct persisted despite the electron deficiency of QM3, although regeneration of QM3 (half-life $>40 \mathrm{hr}$, Figure 3) was greatly suppressed relative to comparable regeneration of QM2 (half-life $<2 \mathrm{hr}$, Figure 2). Behavior of the $\mathrm{dC} \mathrm{N} 3$ and $\mathrm{dA} \mathrm{N} 1$ adducts is consistent with the relative strength of $\mathrm{dC} \mathrm{N} 3$ and $\mathrm{dA} \mathrm{N} 1$ as leaving groups. ${ }^{30}$ The slow formation of the dA N1 adduct combined with its remaining lability prevented its accumulation to the same level as the $\mathrm{dC} \mathrm{N} 3$ adduct or related adducts with QM2. The guanine N7 adduct resulting from QM alkylation and deglycosylation also formed slowly with QMP3, but its yield was similar with both QM2 and QM3.

Destabilization of the QM affects both the kinetics of its formation and the resulting product profile as evident by the stability of the $\mathrm{dC}$ N3-QM3 adduct and the complete absence of a dG $\mathrm{N} 1$ adduct. Adducts of $\mathrm{dG} \mathrm{N}^{2}$ and $\mathrm{dA} \mathrm{N}^{6}$ were still generated by $\mathbf{Q M 3}$ in similar yields and approach the levels of accumulation measured with QM2 (Figure 2). However, these QM3 adducts continue to increase for more than $120 \mathrm{hrs}$ (rather than $10 \mathrm{hr}$ for QM2). The original source of QM3 is mostly consumed by $30 \mathrm{hrs}$, and thus continued generation of the $\mathrm{dG} \mathrm{N}^{2}$ and dA $\mathrm{N}^{6}$ adducts likely derives from the regeneration of $\mathbf{Q M 3}$ from its dA N1 adduct.

\section{Effects of Aromatic Substituents on QM Generation}

A methoxy group was originally attached to the model QM1 in order to examine a broad range of substituent effects on deoxynucleoside adduct stability. Preliminary study of the adduct formed between this electron-rich intermediate and $\mathrm{dC} \mathrm{N} 3$ indicated that it was too labile for convenient analysis. Thus, the weaker electron-donating methyl group was used in place of the $\mathrm{MeO}$ group as described above. As a complement to the range of derivatives available for deoxynucleoside study, a series of $N$-morpholino derivatives were prepared to extend correlations between QM stability and its rate of (re)generation. The morpholino-QM adducts were chosen to replace deoxynucleoside-QM adducts based on the pKa of morpholine's conjugate acid. This property reflects the nucleophile's leaving group ability that, along with QM stability (see above), determines the rate of adduct collapse and QM regeneration (Scheme 3). ${ }^{30,45}$ For nucleophiles with conjugate acids exhibiting pKa's between approximately 4 and 8 , QM regeneration has been detected over hours under physiological conditions. ${ }^{30}$ Morpholine has a conjugate acid pKa of 8.4 which is at the high end of this acidity range and should consequently provide some stability to even highly electron-rich QM precursors. Accordingly, morpholino adducts provided a basis for determining electronic effects of QM reversibility over a greater range of electronic perturbations than available with the deoxynucleosides.

The desired morpholino adducts of substituted QMs were synthesized by a Mannich reaction of 4-methylenemorpholinium halide and the appropriate hydroxylated aromatic prescursor. Substituents influencing QM stability ranged from the strongly electron-donating -OMe group to the electron-withdrawing -COOMe group (Table 2). These groups were placed at the 5position like QMP2 and QMP3 as well as at the 4-position to compare positional differences. The overall trend of adduct stability (QMP4-QMP8) was monitored by conversion of the morpholino adducts to their water adducts (benzylic alcohols, QMA). The range of reactivities observed for this series was even more dramatic than that observed for the deoxynucleoside adducts above. An aqueous solution of the electron-poor adduct QMP4 was fully stable after incubation at $100{ }^{\circ} \mathrm{C}$ for $3 \mathrm{hrs}$ (Table 2). No consumption of QMP4 or formation of QMA3 was detected by HPLC after this harsh treatment. This suggests that QM3 was not generated under these conditions nor was QMP4 subject to direct substitution through a $\mathrm{S}_{\mathrm{N}} 2$ mechanism. This alternative process should not be significantly influenced by remote aromatic substitution, 
and thus QMA formation from the other adducts is indicative of QM generation as detected in a number of related systems ${ }^{14,15,25,45-47}$ rather than direct substitution. Similarly, an alternative $\mathrm{S}_{\mathrm{N}} 1$ mechanism is not consistent with the lack of reactivity of $O$-silyl QMPs and their $O$-methyl derivatives compared to that of their parent phenols ${ }^{14,48}$ since these substituent should all promote such a process almost equally. ${ }^{49}$

An electron-withdrawing -COOMe group placed at the 4-position was not as effective at destabilizing its QMP (QMP5) as the same group placed at the 5-position (QMP4, Table 2). QMP5 was slowly converted to its benzylic alcohol QMA5 albeit heating to $100{ }^{\circ} \mathrm{C}$ was still necessary. The unsubstituted parent QMP6 was somewhat more labile. Formation of QMA1 from trapping of the transient QM1 was observed after heating to only $50^{\circ} \mathrm{C}$. In sharp contrast, the electron rich derivatives containing methoxy substituents (QMP7, QMP8) were very labile with half-lives of only minutes at $22^{\circ} \mathrm{C}$. The sensitivity of QM generation to electronic effects that was first observed for deoxynucleoside adducts is consequently quite general and remarkable for other QM-producing adducts as well. Furthermore, the site of substitution within the QM adduct also plays an important role in its stability. The ortho-QMs characterized in this study were more strongly influenced by substitution at the 5- than 4-position (QMP4 vs. QMP5 and QMP8 vs. QMP7). Inductive and resonance effects from both positions apparently modulate QM stability, but only the 5-position can participate directly in resonance with the nascent exocyclic methylene.

\section{Substituent Effects on Nucleophilic Addition to Quinone Methides}

Substituents used to tune the stability of QM adducts should concurrently effect their electrophilicity and lifetime. The magnitude of these perturbations has now been quantified by laser flash photolysis (LFP). Photochemical activation of hydroxybenzyl alcohols and phenolic Mannich bases (Scheme 5, $\mathrm{L}=\mathrm{OH}$ and $\mathrm{NMe}_{2}$, respectively) has been well described as a mild source of QMs by Wan, ${ }^{50-52}$ Kresge ${ }^{53-55}$ and Saito. ${ }^{56}$ Recently, one of our laboratories has developed an alternative photochemical precursor to QMs, benzyl ammonium salts of phenolic Mannich bases (Scheme 5, $\mathrm{L}={ }^{+} \mathrm{NMe}_{3} \mathrm{I}^{-}$). ${ }^{45}$ In contrast to Mannich bases, these salts are not nucleophilic and do not react with the transient QM. Also, these salts display higher photochemical quantum yields than the corresponding alcohols for QM generation. ${ }^{45}$ The quaternary ammonium salts are therefore ideal for generating a series of $o$-QMs and monitoring their consumption over time in the presence of various nucleophiles.

While Wan, ${ }^{50-52}$ Kresge, ${ }^{53-55,57}$ Richard $^{58-60}$ and our laboratories ${ }^{30,45}$ have investigated the kinetic behavior of the parent $o$-QM (QM1), its para isomer ( $p$-QM) and a few of their derivatives under aqueous conditions, no systematic analysis of substituent effects on QM reactivity has yet been published to our knowledge. Consequently, QMP9-QMP14 were synthesized to examine a diverse range of electronic perturbations, and QM reaction was tested with three prototypical nucleophiles.

Each QM intermediate was generated from its corresponding QMP $(0.2 \mathrm{mM})$ by flash photolysis at $266 \mathrm{~nm}$. QM consumption was then monitored at its $\lambda_{\max }$ under aqueous conditions ( $\mathrm{pH} 7$ ) in the absence and presence of $0.2-50 \mathrm{mM}$ morpholine (buffered at $\mathrm{pH} 9$ with $\mathrm{Na}_{2} \mathrm{CO}_{3}$ ) and 2-mercaptoethanol (buffered at $\mathrm{pH} 7$ with sodium phosphate), alternatively (Table 3). Second order decay rate constants $\left(\mathrm{k}_{2}\right)$ were calculated from the concentration dependence of pseudo-first order kinetic measurements. The rate constants determined under each of the three conditions exhibit parallel trends that are consistent with the behavior of the deoxynucleoside and morpholino adducts. Electron-donating groups significantly stabilize QM. Such groups facilitate QM regeneration from their adducts (Figures 1-3, Table 2) and are now shown to slow nucleophilic addition to the nascent QM as well (Table 3). In a complementary manner, electron-withdrawing groups suppress QM regeneration and strongly promote nucleophilic addition to the nascent QMs. 
The presence of an increasingly strong electron-withdrawing group (5-Cl, 5-COOMe, 5-CN and 5- $\mathrm{NO}_{2}$ ) progressively decreased $\mathrm{QM}$ lifetime as evident by the increasing values of $\mathrm{k}_{2}$. The 5- $\mathrm{NO}_{2}(\mathbf{Q M 1 4})$ in particular resulted in a $\mathrm{k}_{2}$ for the hydration reaction that was several orders of magnitude greater than that of the parent QM1. In contrast, the electron-donating ability of the 5-MeO group decreased the rate of its QM (QM7) consumption vs. the parent QM1 by 4- to 5-fold. Although the rates of QM decay were much faster in the added presence of strong nucleophiles represented here by morpholine and 2-mercaptoethanol, their general sensitivity to electron-withdrawing and donating substituents remains nearly equivalent. Still, the relatively selectivity for the individual nucleophiles decreases with increasing reactivity of the QM. Such data is consistent with the much maligned reactivity-selectivity principle despite the lack of reaction controlled by diffusion. 61

The sensitivity of QM reaction to substituents was also examined by its free energy relationship $\left[\ln \left(k y / k_{H}\right)\right]$ for addition of morpholine (Figures $\left.4 a, a^{\prime}\right)$, water (Figure $\left.4 b, b^{\prime}\right)$ and 2-

mercaptoethanol (Figure $\left.4 \mathrm{c}, \mathrm{c}^{\prime}\right)$. Linear correlations were slightly better with Hammett $\sigma_{\mathrm{p}}{ }^{-}$ constants (Figures $4 \mathrm{a}, \mathrm{b}, \mathrm{c}$ ) than with Hammett $\sigma_{\mathrm{p}}$ constants (Figures $4 \mathrm{a}^{\prime}, \mathrm{b}^{\prime}, \mathrm{c}^{\prime}$ ). The $\sigma_{\mathrm{p}}{ }^{-}$constants were originally set by changes in the pKa of para substituted phenols and are now used for systems with strong resonance interaction between substituent and reaction center. Such a case is proposed for reactive QMs that appear to develop a degree of aromaticity in the transitionstate (TS) with negative charge efficiently stabilized by delocalization over the former oxygen carbonyl group and Y substituent (Scheme 6). Such resonance contributions are likely even greater for substituents at the 5-position since they may influence the exocyclic methylene of the QM more directly. Preliminary support for this prediction is evident by the greater influence of substituents at the 5- vs. 4-position as summarized in Table 2.

Hansch had previously noted that $\sigma_{\mathrm{p}}{ }^{-}$constants often yield better correlations than $\sigma_{\mathrm{p}}$ when resonance interaction develops between the substituent and the reaction center, and the resulting magnitude of $\rho$ has provided insight into reaction mechanisms. ${ }^{49}$ For QM addition, the linear free energy correlations are positive and large. The values of $\rho$ equal 3.0, 5.9 and 5.4 for morpholine, water and 2-mercaptoethanol, respectively (Figure 4a,b,c). In comparison, $\rho$ values for the equilibrium acidity of phenol in water and DMSO are 2.1 and 5.3, respectively. 62,63 The equilibrium acidity of $p$-substituted benzyltriphenylphosphonium cations to form the corresponding ylide in DMSO exhibited a $\rho$ of $4.78 .{ }^{64}$ Much larger values of $\rho$ (12 and 10) were determined for substituent effects on the acidity of a benzylic hydrogen in toluene and 10-substituted-9-methylanthracene derivatives in DMSO, respectively. ${ }^{65,66}$ The intermediate values of $\rho$ for QM addition in water is then suggestive of significant anionic character in the TS. The lower value for the phosphonium salt vs. toluene was considered by Bordwell to indicate a diminished charge delocalization on the salt due to coulombic and polarization contributions by the triphenylphosphonium group. ${ }^{64}$ The smaller $\rho$ value of morpholine vs. those of water and 2- mercaptoethanol may also be explained by the electrostatics of the developing positive charge on the nitrogen nucleophile.

\section{Conclusions}

Formation of QMs had previously demonstrated a dependence on the strength of the leaving group attached to the benzylic position of its precursor when studying a model $o$-QM in the presence of biological nucleophiles (Scheme 3). ${ }^{30,45}$ Now, both the formation and subsequent reaction of QMs have also been shown to be highly responsive to the presence of electronwithdrawing and donating groups. All trends in reactivity are consistent with the electron deficient nature of the QM intermediate. Electron donating groups greatly facilitate initial QM generation and its subsequent regeneration from adducts formed by the nucleophiles of deoxynucleosides that also function as good leaving groups. Conversely, electron withdrawing groups greatly suppress initial formation of QM and suppress its regeneration from the 
reversible deoxynucleoside adducts. These properties similarly extend to nucleophiles and leaving groups beyond those of DNA and provide a foundation for predicting the general behavior of QM stability and selectivity. In a complementary manner, electron-rich QMs react much more slowly but more selectively with nucleophiles than do the electron-poor QMs. These fundamental characteristics provide the basis for explaining the product profiles observed after DNA has been exposed to various QMs. In the future, these same characteristics may be used to fine-tune the stability and reactivity of QM conjugates for target-promoted and gene-specific alkylation. ${ }^{15}$ An equivalent approach may also be used to optimize the kinetics and sensitivity of polymers based on QMs to disassemble for drug release. ${ }^{32-34}$

\section{Experimental Procedures for Quinone Methide Reaction}

\section{Kinetic Studies with Individual Deoxynucleosides}

To a aqueous solution ( $70 \mu \mathrm{L}$ ) of $4 \mathrm{mM}$ phenol, $0.5 \mathrm{mM}$ deoxynucleoside, $10 \mathrm{mM}$ potassium phosphate $\mathrm{pH}$ 7, $500 \mathrm{mM} \mathrm{KF}$ was added the quinone methide precursor (QMP1, QMP2 and QMP3 alternatively) in DMF ( $30 \mu \mathrm{L}$ ) yielding a final concentration of $25 \mathrm{mM}$. The reactions were incubated at $37^{\circ} \mathrm{C}$ and, at the indicated times, analyzed directly by reverse phase HPLC (C-18, Varian, Microsorb-MV 300, $5 \mu \mathrm{m}$ particle size, $250 \mathrm{~mm} \times 4.6 \mathrm{~mm}$ ) using a gradient of $3 \% \mathrm{CH}_{3} \mathrm{CN}, 9.7 \mathrm{mM}$ TEAA, to $25 \% \mathrm{CH}_{3} \mathrm{CN}, 7.5 \mathrm{mM}$ TEAA at $1 \mathrm{~mL} / \mathrm{min}$ over $66 \mathrm{~min}$. For QMP1 reaction, TEAA was adjusted to $\mathrm{pH} 4$, and for QMP2 and QMP3, the TEAA was adjusted to $\mathrm{pH}$ 6. Product formation was monitored by integrating the elution profile at 260 $\mathrm{nm}$ generated by a diode array detector and normalizing its signal by the relative $\varepsilon_{260}$ of each product and absorbance of an internal standard (phenol).

\section{Competition Studies in the Presence of all Deoxynucleosides}

To a aqueous solution ( $70 \mu \mathrm{L}$ ) of $4 \mathrm{mM}$ phenol, $0.25 \mathrm{mM}$ of dA, dC, dG, and $\mathrm{T}$ ( $1 \mathrm{mM}$ total $\mathrm{dN}), 10 \mathrm{mM}$ potassium phosphate $\mathrm{pH} 7,500 \mathrm{mM} \mathrm{KF}$, was added the quinone methide precursor (QMP1, QMP2 and QMP3 alternatively) in DMF (30 $\mu \mathrm{L})$ yielding a final concentration of $25 \mathrm{mM}$. Reactions were incubated at $37^{\circ} \mathrm{C}$ and analyzed as described above.

\section{Kinetics of Quinone Methide Regeneration and Benzylic Alcohol Formation from the Morpholino-quinone Methide Adducts}

A stock solution of QMP6 in acetonitrile was diluted with water:acetonitrile (1:1) to yield final concentration of $1.0 \mathrm{mM}$, and anisole $(0.6 \mathrm{mM})$ was added as internal standard. The resulting solution was incubated for $240 \mathrm{~min}$ at $50{ }^{\circ} \mathrm{C}$. Every $5 \mathrm{~min}$, an aliquot $(200 \mu \mathrm{L})$ was removed and cooled at $-20^{\circ} \mathrm{C}$ in a ice-salt bath prior to analysis by reverse phase HPLC (C-18, Intersil ODS-2, $5 \mu \mathrm{m}$, column dimension: $\varphi=4.6 \mathrm{~mm}$, length $=250 \mathrm{~mm}, \varphi=10.0 \mathrm{~mm}$, length $=250$ $\mathrm{mm})$ with $50 \%$ aq $\mathrm{CH}_{3} \mathrm{CN}(1 \mathrm{~mL} / \mathrm{min})$. The benzylic alcohol (QMA1) was detected with a variable-wavelength detected the alcohol and compared to an authentic sample. Reaction of the adducts (QMP4, QMP5, QMP7 and QMP8) was monitored similarly although reaction time and temperature as indicated in Table 1 to detect the benzylic alcohols (QMA3, QMA5, QMA7 and QMA8).

\section{Laser Flash Photolysis (LFP) to Determine the Second Order Rate Constants for Addition of Water, Morpholine and 2-Mercaptoethanol to a Range of Quinone Methides}

Kinetic studies of nucleophilic addition to QMs were carried out at $25^{\circ} \mathrm{C}$, in pure water for the hydration reaction and in the added presence of 2-mercaptoethanol ( $\mathrm{pH} 7$ ) and morpholine (adjusted to $\mathrm{pH} 9$ by addition of $\mathrm{Na}_{2} \mathrm{CO}_{3}$ ) alternatively. The $\mathrm{pH}$ of each solution was measured using an Orion SA520 pH meter with a 8102 Ross electrode. QM1, QM5, QM8, QM11, QM13 and QM14 were generated by flashing a dilute solutions of QMP9-QMP14 $\left(2-5 \times 10^{-4} \mathrm{M}\right)$. Disappearance of the QMs was followed under pseudo first-order conditions by monitoring 
the absorbance decrease at the maximum wavelength reported in Table 3. Pseudo-first-order rate constants $\left(k_{\text {obsd }}\right)$ were obtained from the fitting the absorbance data to a single exponential function and were reproducible to $+/-5 \%$. The second-order rate constants $k_{2}\left(\mathrm{M}^{-1} \mathrm{~s}^{-1}\right)$ for addition of nucleophiles to the QMs were determined as the least-squares linear slopes of $k_{\text {obsd }}$ vs total concentration of the nucleophile varied between $5 \times 10^{-2}$ to $2 \times 10^{-4} \mathrm{M}$.

\section{Laser Flash Photolysis Apparatus}

The laser pulse photolysis apparatus consisted of a Nd:YAG laser used at the fourth harmonic of its fundamental wavelength. It delivers a maximum power of $10 \mathrm{~mJ}$ at $266 \mathrm{~nm}$ with $10 \mathrm{~ns}$ pulse duration. The monitoring system was arranged in a cross-beam configuration and consisted of a $275 \mathrm{~W}$ Xe arc lamp, an F/3.4 monochromator, and a five-stage photomultiplier supplied by Applied Photophysics. Signals were captured by a Hewlett-Packard 54510A digitizing oscilloscope, and the data was processed on a 486-based computer system using software developed in-house. Solutions for analysis were placed in a fluorescence cuvette $(d=10 \mathrm{~mm})$ and adjusted to an absorbance of 1.5.

\section{Supplementary Material}

Refer to Web version on PubMed Central for supplementary material.

\section{Acknowledgements}

This research was supported in part by the National Institutes of Health (CA81571, SER), the Howard Hughes Medical Institute through the Undergraduate Biological Sciences Education Program (KNF, CHM) and Pavia University (FAR 2004, MF). We thank Dr. Yui-fai Yam for help with NMR characterization of the deoxynucleoside adducts.

\section{References}

1. Zewail-Foote M, Hurley LH. J Am Chem Soc 2001;123:6485-6495. [PubMed: 11439034]

2. Mattes WB, Hartley JA, Kohn KW. Nucleic Acids Res 1986;14:2971-2987. [PubMed: 3960738]

3. Kohn KW, Hartley JA, Mattes WB. Nucleic Acids Res 1987;15:10531-10549. [PubMed: 3697095]

4. Colvin OM, Friedman HS, Gamcsik MP, Fenselau C, Hilton J. Adv Enz Regula 1993;33:19-26.

5. Dedon PC, Plastaras JP, Rouzer CA, Marnett LJ. Proc Natl Acad Sci USA 1998;95:11113-11116. [PubMed: 9736698]

6. Mao H, Schnetz-Boutaud NC, Weisenseel JP, Marnett LJ, Stone MP. Proc Natl Acad Sci USA 1999;96:6615-6620. [PubMed: 10359760]

7. Plastaras JP, Riggins JN, Otteneder M, Marnett LJ. Chem Res Toxicol 2000;13:1235-1242. [PubMed: 11123964]

8. Riggins JN, Daniels S, Rouzer CA, Marnett LJ. J Am Chem Soc 2004;126:8237-8243. [PubMed: 15225065]

9. Boger DL, Johnson DS. Angew Chem, Int Ed Engl 1996;35:1438-1474.

10. Lee SJ, Seaman FC, Sun D, Xiong H, Kelly RC, Hurley LH. J Am Chem Soc 1997;119:3434-3442.

11. Boger DL, Yun W. J Am Chem Soc 1993;115:9872-9873.

12. Boger DL, Garbaccio RM. Acc Chem Res 1999;32:1043-1052.

13. Asai A, Nagamura S, Saito H, Takahashi I, Nakano H. Nucleic Acids Res 1994;22:88-93. [PubMed: 8127659]

14. Veldhuyzen WF, Pande P, Rokita SE. J Am Chem Soc 2003;125:14005-14013. [PubMed: 14611237]

15. Zhou Q, Rokita SE. Proc Natl Acad Sci USA 2003;100:15452-15457. [PubMed: 14673113]

16. Wang P, Liu R, Wu X, Ma H, Cao X, Zhou P, Zhang J, Weng X, Zhang XL, Zhou X, Weng L. J Am Chem Soc 2003;125:1116-1117. [PubMed: 12553783]

17. Richter SN, Maggi S, Mels SC, Palumbo M, Freccero M. J Am Chem Soc 2004;126:13973-13979. [PubMed: 15506758] 
18. Wang P, Song Y, Zhang L, He H, Zhou X. Curr Med Chem 2005;12:2893-2913. [PubMed: 16305478]

19. Lewis MA, Yoerg DG, Bolton JL, Thompson JA. Chem Res Toxicol 1996;9:1368-1374. [PubMed: 8951242]

20. Fan PW, Zhang F, Bolton JL. Chem Res Toxicol 2000;13:45-52. [PubMed: 10649966]

21. Tomasz M. Chem Biol 1995;2:575-579. [PubMed: 9383461]

22. Zhou Q, Zuniga MA. Chem Res Toxicol 2005;18:382-388. [PubMed: 15720146]

23. Angle SR, Yang W. J Org Chem 1992;57:1092-1097.

24. Angle SR, Rainer JD, Woytowicz C. J Org Chem 1997;62:5884-5892.

25. Pande P, Shearer J, Yang J, Greenberg WA, Rokita SE. J Am Chem Soc 1999;121:6773-6779.

26. Veldhuyzen W, Lam Y-f, Rokita SE. Chem Res Toxicol 2001;14:1345-1351. [PubMed: 11559052]

27. Veldhuyzen WF, Shallop AJ, Jones RA, Rokita SE. J Am Chem Soc 2001;123:11126-11132. [PubMed: 11697955]

28. Freccero M, Di Valentin C, Sarzi-Amadè M. J Am Chem Soc 2003;125:3544-3553. [PubMed: 12643716]

29. Freccero M, Gandolfi R, Sarzi-Amadè M. J Org Chem 2003;68:6411-6423. [PubMed: 12895079]

30. Weinert EE, Frankenfield KN, Rokita SE. Chem Res Toxicol 2005;18:1364-1370. [PubMed: 16167827]

31. Wakselman M. New J Chem 1983;7:439-447.

32. de Groot FMH, Albrecht C, Koekkoek R, Beusker PH, Scheeren HW. Angew Chem Int Ed 2003;42:4490-4494.

33. Li SJ, Szalai ML, Kevwitch RM, McGrath DV. J Am Chem Soc 2003;125:10516-10517. [PubMed: 12940723]

34. Shamis M, Lode HN, Shabat D. J Am Chem Soc 2004;126:1726-1731. [PubMed: 14871103]

35. Van De Water RW, Pettus TRR. Tetrahedron 2002;58:5367-5405.

36. Amouri H, Besace Y, Le Bras J. J Am Chem Soc 1998;120:6171-6172.

37. Amouri H, le Bras J. Acc Chem Res 2002;35:501-510. [PubMed: 12118989]

38. Rabin O, Vigalok A, Milstein D. Chem Eur J 2000;6:454-457.

39. Vigalok A, Milstein D. Acc Chem Res 2001;34:798-807. [PubMed: 11601964]

40. Filar LJ, Winstein S. Tet Lett 1960:9-16.

41. Loubinoux B, Miazimbakana J, Gerardin P. Tetrahedron Let 1989;30:1939-1942.

42. Bolton JL, Valerio LG, Thompson JA. Chem Res Toxicol 1992;5:816-822. [PubMed: 1489934]

43. Bolton JL, Comeau E, Vukomanovic V. Chem Biol Interact 1995;95:279-290. [PubMed: 7728898]

44. Rokita SE, Yang J, Pande P, Greenberg WA. J Org Chem 1997;62:3010-3012. [PubMed: 11671669]

45. Modica E, Zanaletti R, Freccero M, Mella M. J Org Chem 2001;66:41-52. [PubMed: 11429928]

46. Zhou Q, Pande P, Johnson AE, Rokita SE. Bioorg Med Chem 2001;9:2347-2354. [PubMed: 11553475]

47. Kumar D, Veldhuyzen WF, Zhou Q, Rokita SE. Bioconj Chem 2004;15:915-922.

48. Zeng Q, Rokita SE. J Org Chem 1996;61:9080-9081.

49. Hansch C, Leo A, Taft RW. Chem Rev 1991;91:165-195.

50. Wan P, Barker B, Diao L, Fischer M, Shi Y, Yang C. Can J Chem 1996;74:465-475.

51. Diao L, Yang C, Wan P. J Am Chem Soc 1995;117:5396-5370.

52. Brousmiche DW, Xu M, Lukerman M, Wan P. J Am Chem Soc 2003;125:12961-12970. [PubMed: 14558845]

53. Chiang Y, Kresge AJ, Zhu Y. J Am Chem Soc 2001;123:8089-8094. [PubMed: 11506565]

54. Chiang Y, Kresge AJ, Zhu Y. J Am Chem Soc 2002;124:717-722. [PubMed: 11804503]

55. Chiang Y, Kresge AJ, Zhu Y. J Am Chem Soc 2002;124:6349-6356. [PubMed: 12033864]

56. Nakatani K, Higashida N, Saito I. Tet Lett 1997;38:5005-5008.

57. Chiang Y, Kresge AJ. Org Biomol Chem 2004;2:1090-1092. [PubMed: 15034634]

58. Toteva MM, Moran M, Amyes TL, Richard JP. J Am Chem Soc 2003;125:8814-8819. [PubMed: 12862476] 
59. Richard JP, Toteva MM, Crugeiras J. J Am Chem Soc 2000;122:1664-1674.

60. Toteva MM, Richard JP. J Am Chem Soc 2000;122:11073-11083.

61. Mayr H, Ofial AR. Angew Chem Int Ed 2006;45:1844-1854.

62. Hammett, LP. Physical Organic Chemistry. McGraw-Hill; New York: 1940. Ch 7.

63. Bordwell FG, McCallum RJ, Olmstead WN. J Org Chem 1984;49:1424-1427.

64. Zhang XM, Fry AJ, Bordwell FG. J Org Chem 1996;61:4101-4106. [PubMed: 11667288]

65. Zhang XM, Bordwell FG, Bares JE, Cheng JP, Petrie B. J Org Chem 1993;58:3051-3059.

66. Bordwell FG, Zhang XM, Cheng JP. J Org Chem 1993;58:6410-6416. 


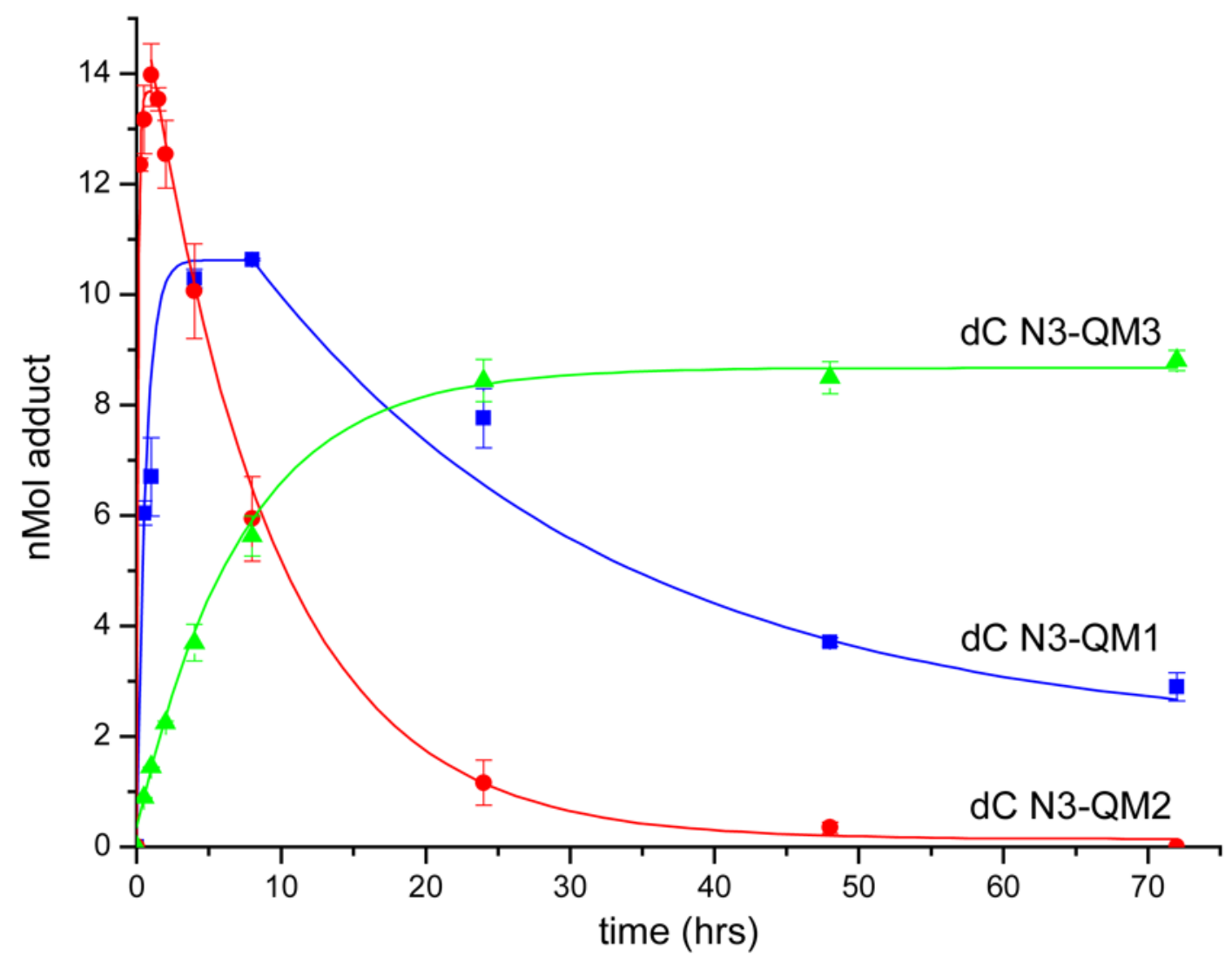

Figure 1.

Formation and decomposition of quinone methide adducts of $\mathrm{dC} \mathrm{N} 3$. Reaction conditions and product analysis are described in the Experimental Procedures. Each point represents the average of at least three independent determinations and was fit to exponential processes for highlighting the net trends of the data. The indicated error derives from the standard deviations. 


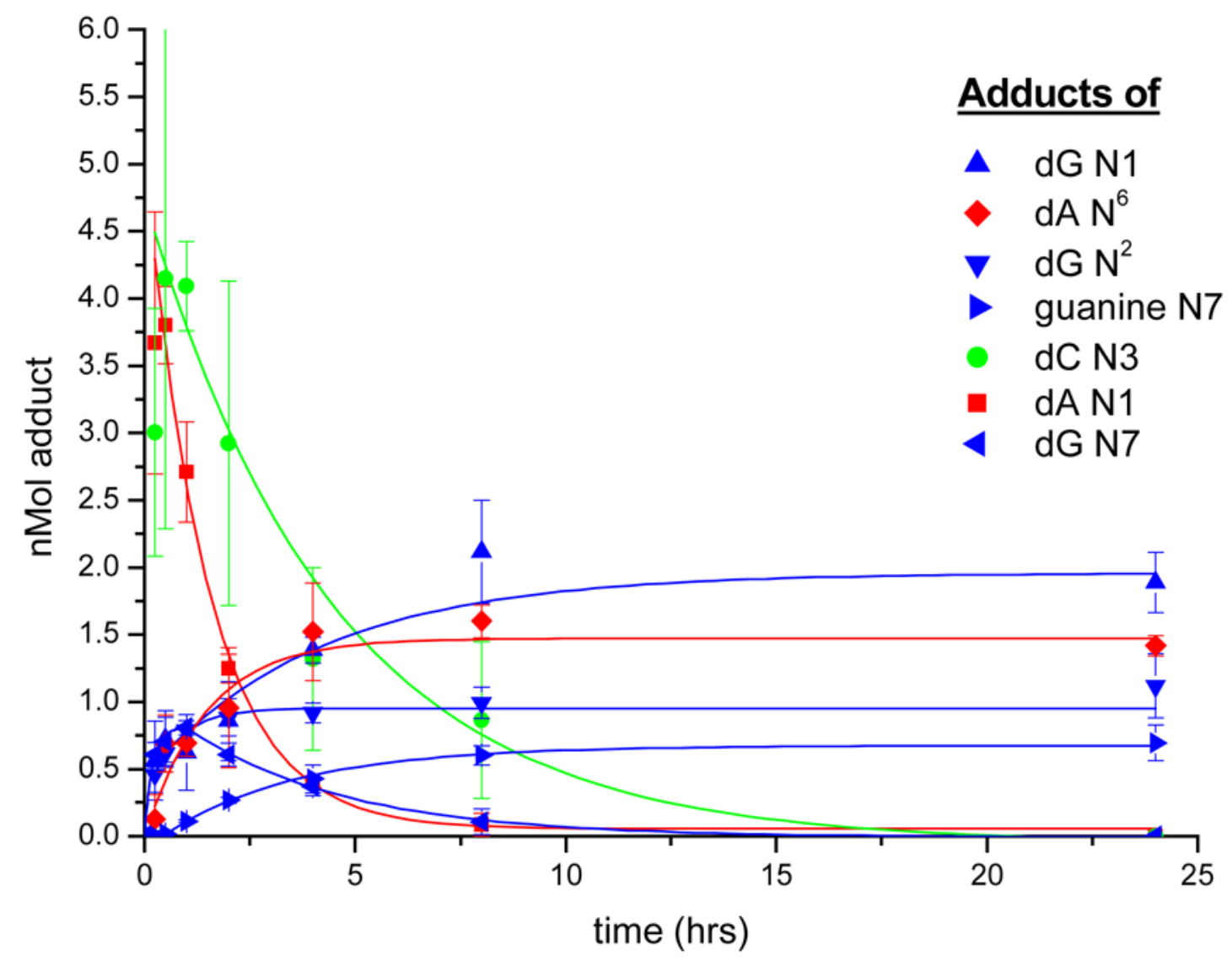

Figure 2.

Time-dependent profile of adducts formed by the electron-rich QM2 and deoxynucleosides. Reaction conditions and product analysis are identical to those used for Figure 1. Again, each point represents the average of at least three independent determinations and was fit to exponential processes for highlighting the net trends of the data. The indicated error derives from the standard deviations. 


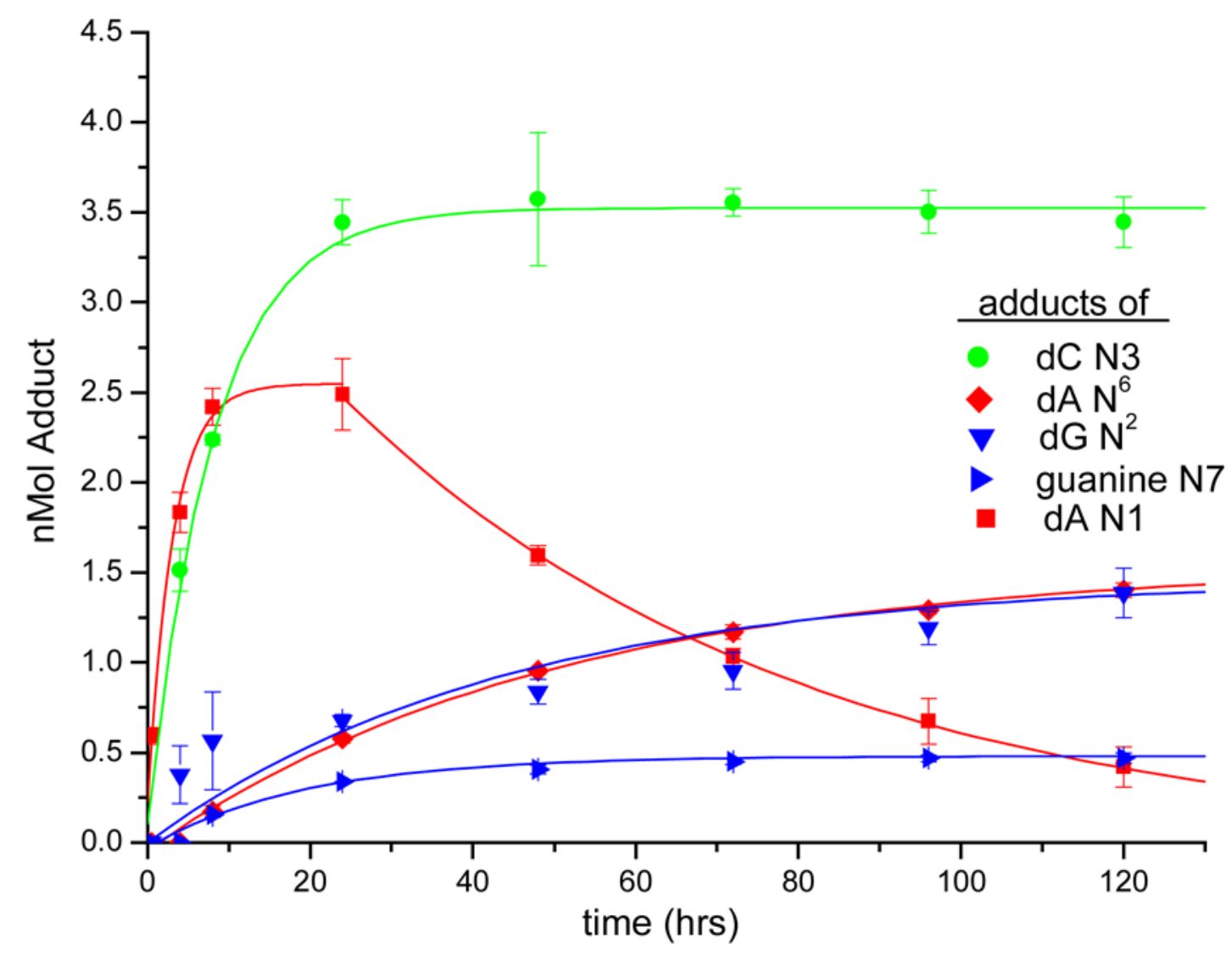

Figure 3.

Time-dependent profile of adducts formed by the electron-poor QM3 and deoxynucleosides. Reaction conditions and product analysis are identical to those used for Figure 1. Again, each point represents the average of at least three independent determinations and was fit to exponential processes for highlighting the net trends of the data. The indicated error derives from the standard deviations. 

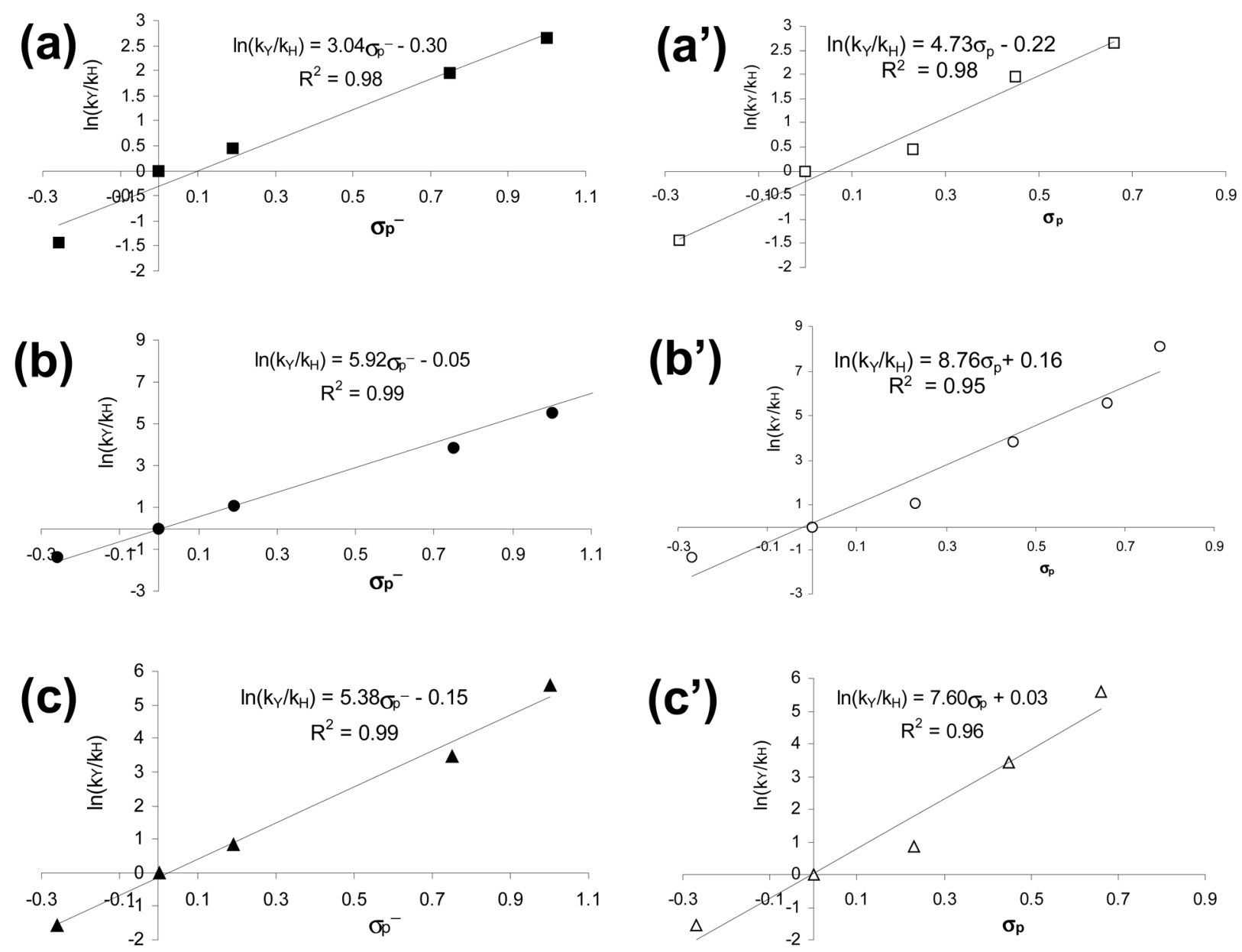

Figure 4.

Free energy relationships $\ln \left(\mathrm{k}_{\mathrm{y}} / \mathrm{k}_{\mathrm{H}}\right)$ vs Hammet $\sigma_{\mathrm{p}}{ }^{-}(\mathrm{a}, \mathrm{b}, \mathrm{c})$ and Hammet $\sigma_{\mathrm{p}}\left(\mathrm{a}^{\prime}, \mathrm{b}^{\prime}, \mathrm{c}^{\prime}\right)$ for the addition reactions of morpholine $\left(\mathrm{a}, \mathrm{a}^{\prime}\right)$, water $\left(\mathrm{b}, \mathrm{b}^{\prime}\right)$ and thiol $\left(\mathrm{c}, \mathrm{c}^{\prime}\right)$. 

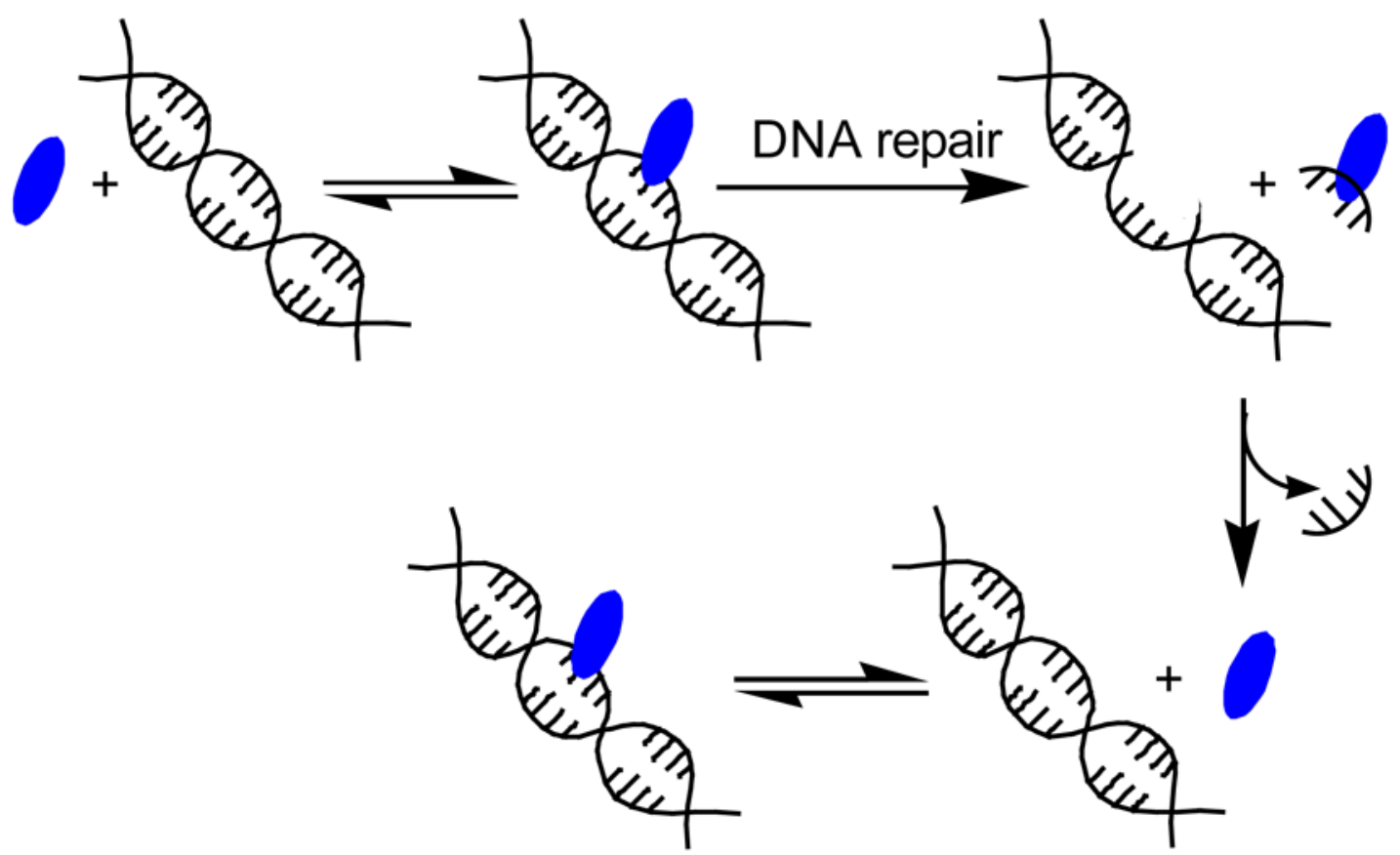

Scheme 1.

Repair and Reformation of a DNA Adduct 


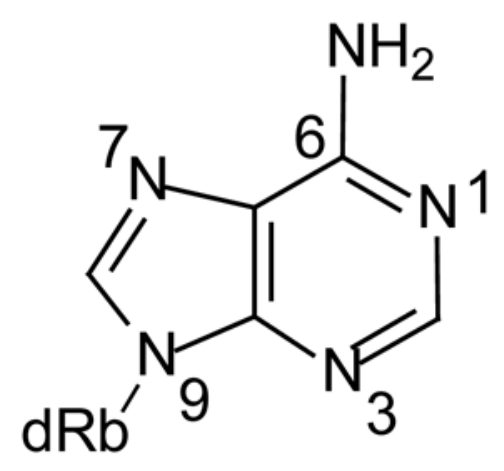

$d A$

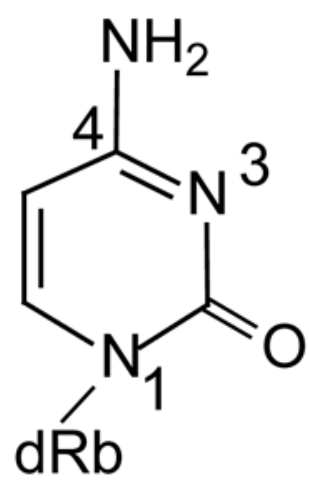

$\mathrm{dC}$

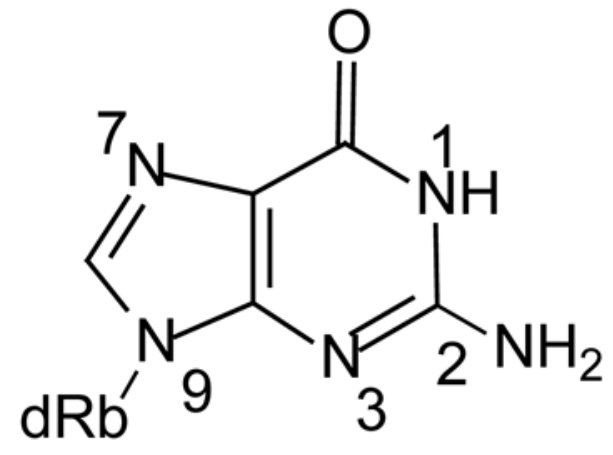

dG

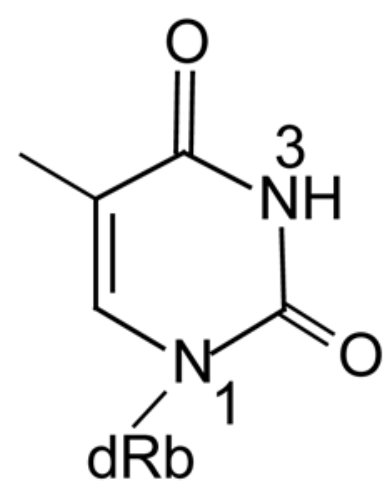

$\mathrm{T}$

Scheme 2.

Nucleobase Structure 


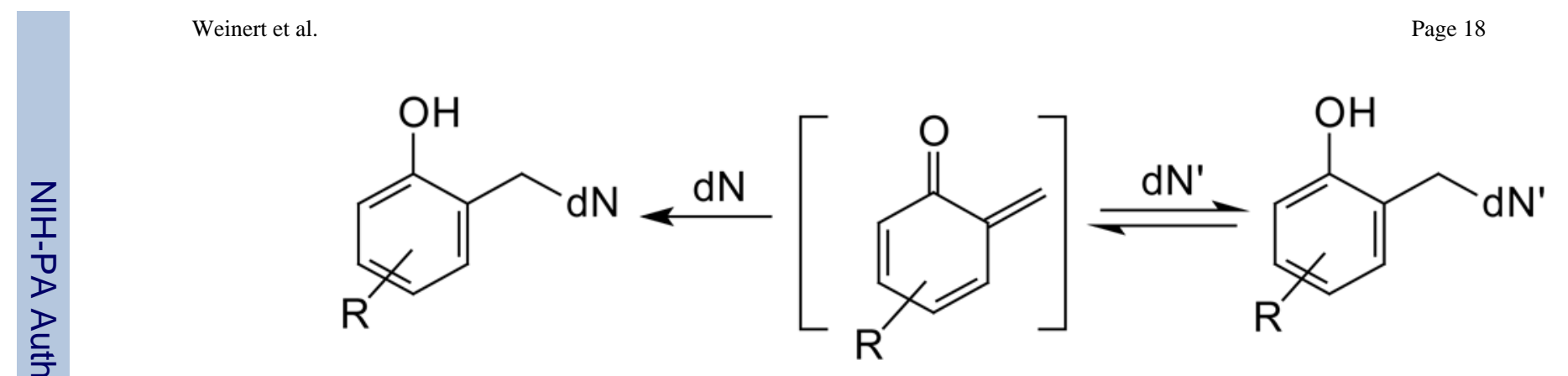

Scheme 3.

Reversible and Irreversible Formation of QM Adducts 


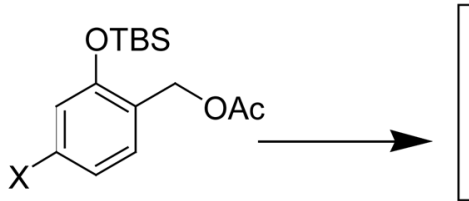<smiles>[X]C1=CC(=C)C(=O)C=C1</smiles><smiles>CC(C)(C)[Si](C)(C)C=C[AsH3-]</smiles>
quinone methide precursor

QMP1

QMP2

QMP3

$\mathrm{X}=\mathrm{H}$

$\mathrm{X}=\mathrm{Me}$

quinone methide

QM1

QM2

QM3

Scheme 4.

QM generation from Silyl-protected Precursors 

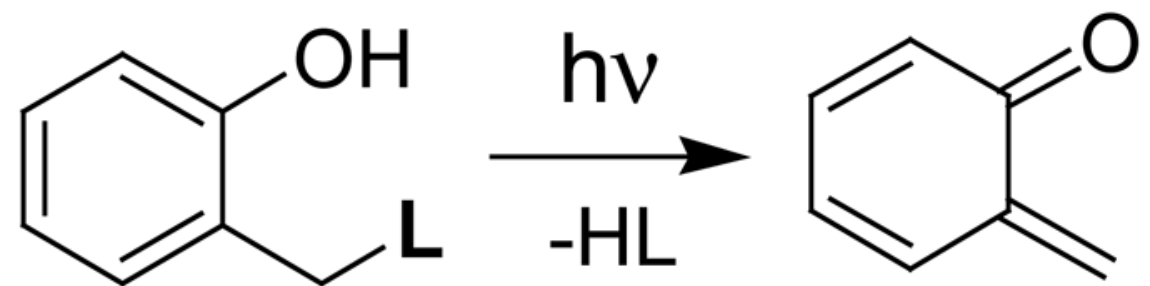

O-QM
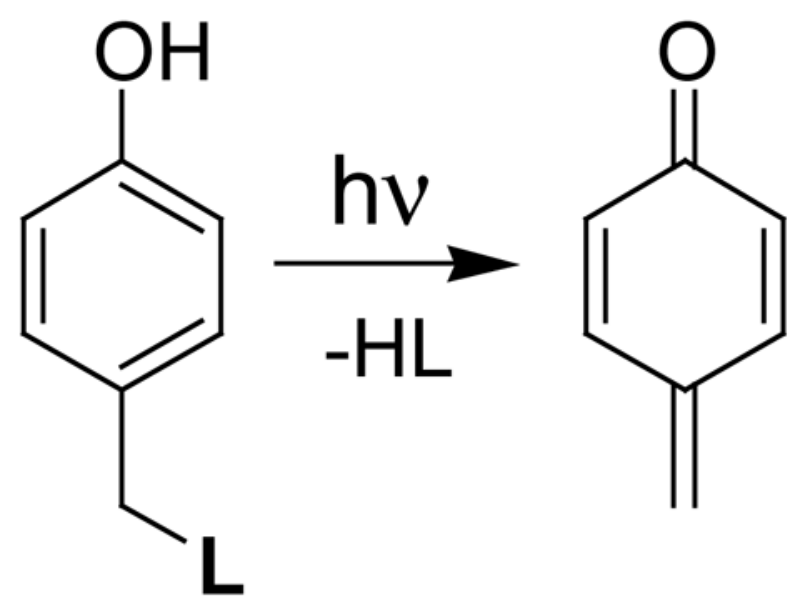

$p-Q M$

$$
\mathbf{L}=\mathrm{OH}, \mathrm{NMe}_{2}, \stackrel{\oplus}{\mathrm{N}} \mathrm{Me}_{3} \mathrm{l}^{\ominus}
$$

Scheme 5.

Photogeneration of QM 


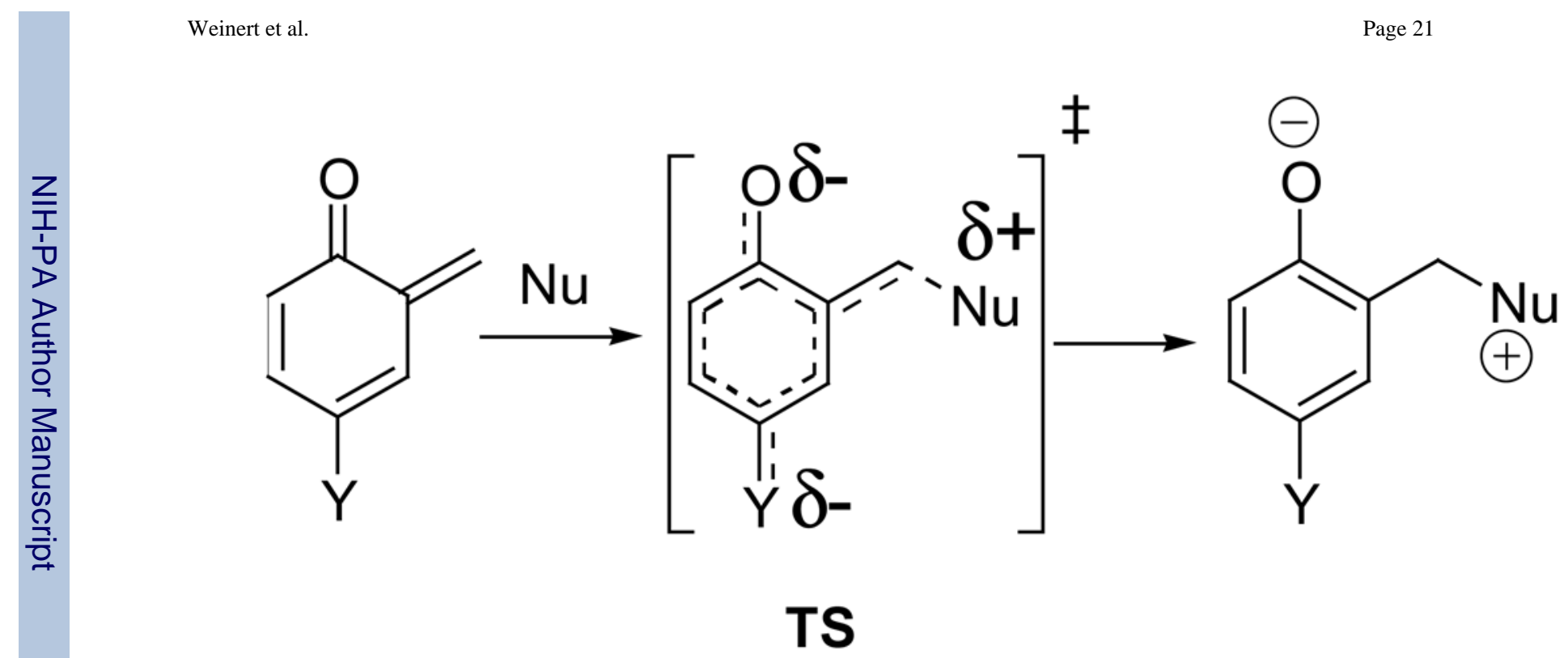

Scheme 6.

Aromaticity Develops in the Transition-state of QM Addition 


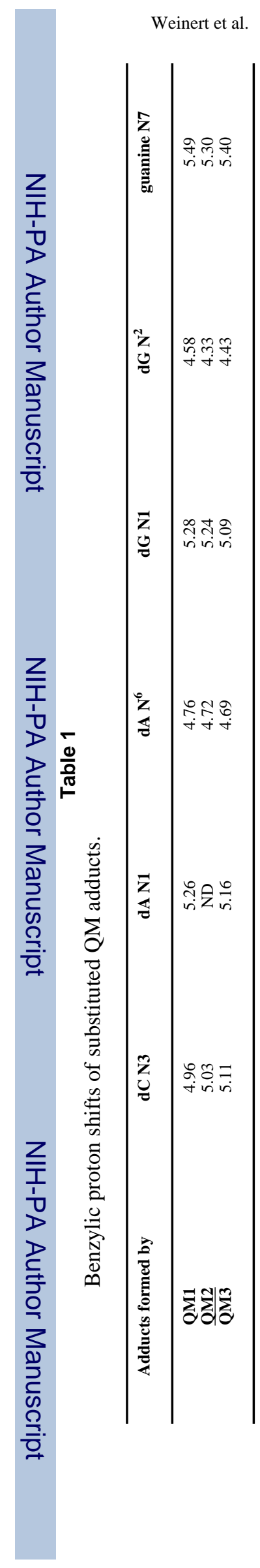

Page 22 


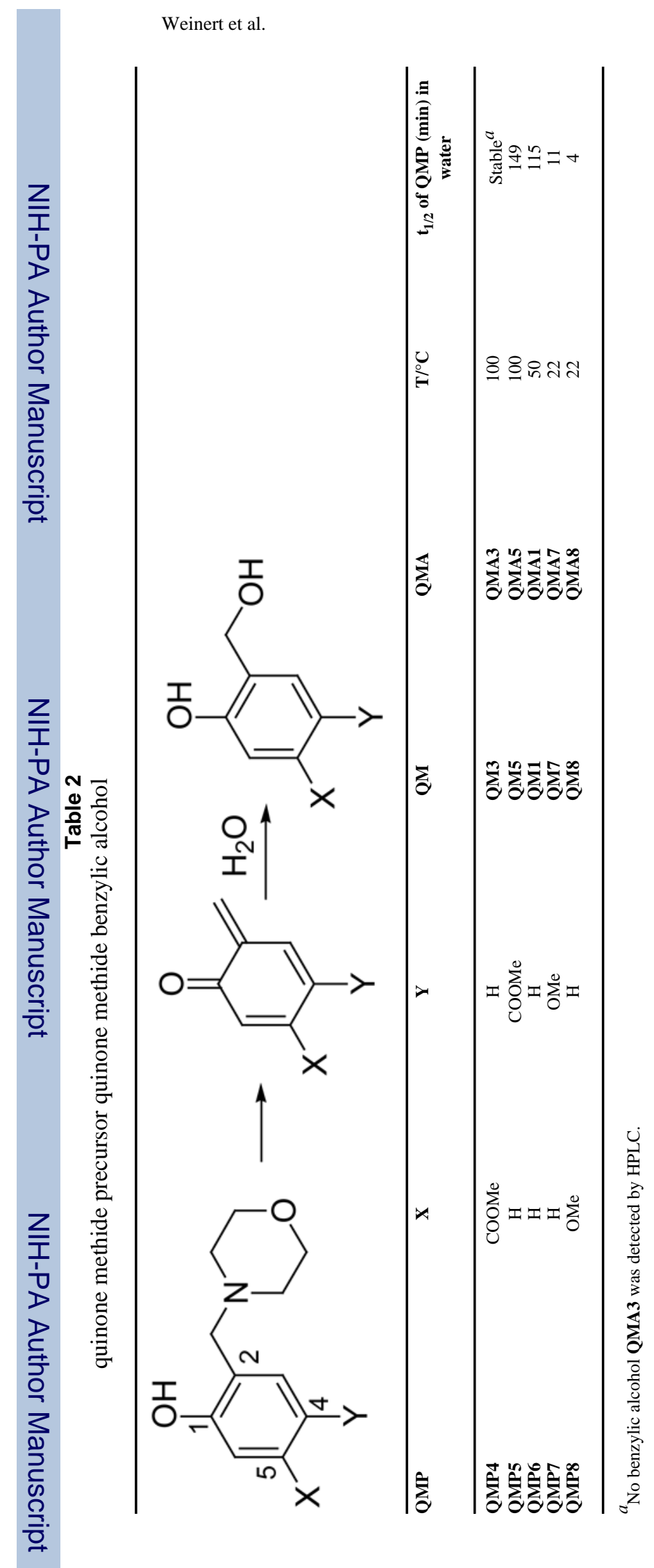

Page 23

$J$ Am Chem Soc. Author manuscript; available in PMC 2008 September 16. 

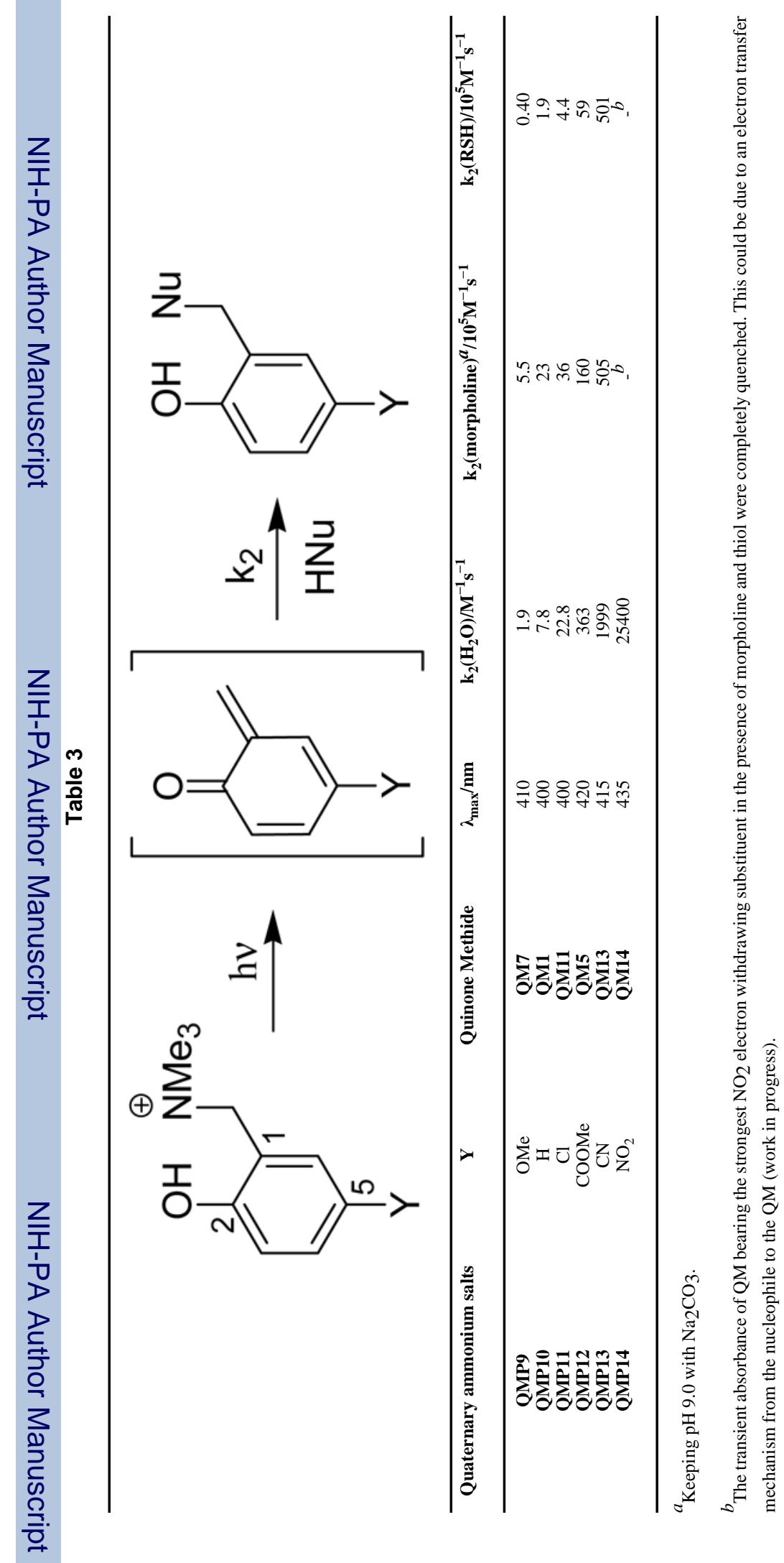